\title{
太平正长石的微结构与 ${ }^{29} \mathrm{Si} N M R$ 谱研究 ${ }^{*}$
}

\author{
薛纪越(1) 坽玲棣(1) 郭九香(1) 李丽云(4) 李齐(1)
}

(1)南京大学固体微结构物理实验室, (2)地球科学系, 南京 210093; (3)中国科学院广州地球化学研究所,

广州 510640; (4)中国科学院武汉物理研究所波谱与原子物理开放实验室, 武汉 430074)

\section{关链词正长石 微结构 ${ }^{29} \mathrm{Si} \mathrm{NMR}$ 橎 安徽太平}

周玲棣等 ${ }^{[1]}$, 对一些用 $\mathrm{X}$ 射线粉末衍射法确定为正长石的晶体进行了 ${ }^{29} \mathrm{Si}$ 和 ${ }^{27} \mathrm{Al}$ 核磁共 振谱研究, 发现这些正长石的 ${ }^{29} \mathrm{Si}$ NMR 谱并不象一些人 ${ }^{[2]}$ 所描述的那样是两个分别占 $T_{2}$ 和 $1 / 2 T_{1}$ 位置的峰, 而具有 3 个峰. 笔者对安徽太平花岗岩岩墙中正长石斑晶的微结构与 ${ }^{29} \mathrm{Si} N \mathrm{NMR}$ 谱进行了研究, 以期对该正长石的 ${ }^{29} \mathrm{Si} \mathrm{NMR}$ 谱具有 3 个峰作出解释.

\section{1 样品命名}

本文讨论的样品采自安徽太平县城西南花岗岩岩墙中, 以斑晶形式产出. 由于风化作用, 晶体自然从岩石中完好剥落. 个体长度至少在 $2 \mathrm{~cm}$ 以上, 沿 $c$ 轴延长的厚板状, 发育的单形 有 $\{010\} 、\{001\} 、\{110\} 、\{130\} 、\{20 \overline{1}\}$ 和 $\{111\}$ 等．几乎每个斑晶都发育着卡斯巴律双晶. 电子 探针成分分析结果以及端员组分的摩尔百分含量列于表 1 . 在偏光显微镜下不显格子双晶. 包裹着半自形的钠长石, 并有脉状文象长英质出溶物. 用旋转台雉光法测得的光轴角 $(-2 \mathrm{~V})$ 在 $36^{\circ} \sim 41^{\circ}$ 范围内, $\perp(010) \wedge N_{g}=0^{\circ}$, 光性上呈单斜对称的特点. 据此, 可确定该长石的 $\mathrm{Si}-\mathrm{Al}$ 光性单斜有序率为 0.95 .

表 1 太平正长石电子探针分析结果以及端员组分摩尔百分含量")

\begin{tabular}{cccccccccc}
\hline $\mathrm{SiO}_{2}$ & $\mathrm{Al}_{2} \mathrm{O}_{3}$ & $\mathrm{FeO}^{b}$ & $\mathrm{CaO}$ & $\mathrm{Na}_{2} \mathrm{O}$ & $\mathrm{K}_{2} \mathrm{O}$ & 总和 & $\mathrm{Or}$ & $\mathrm{Ab}$ & $\mathrm{An}$ \\
\hline 65.31 & 19.01 & 0.03 & 0.00 & 0.24 & 15.46 & 100.05 & 97.6 & 2.4 & 0 \\
\hline
\end{tabular}

a)两个分析点的波谱分析结果平均值

b) 全铁

从 $\mathrm{X}$ 射线粉末衍射图谱看, 太平长石的 131 与 $1 \overline{3} 1$ 峰没有分离, 因而它是 $\mathrm{X}$ 射线意义上 的单斜晶体. 根据 060 和 $\overline{2} 04$ 衍射峰位 $(2 \theta)$ 计算得到 $\mathrm{Al}$ 在两个 $T_{1}$ 位置的占位率为 0.70 , 即 $2 t_{1}=0.70$. 根据 $\mathrm{Ribbe}^{[3]}$ 对单斜长石命名的原则, 可以把太平钟长石列为低透长石的范畴. 这与光轴角定名的结果相符. 从结构上讲, 低透长石与正长石之间并没有区别, 而只是一种人 为的划分. Ribbe 将 $2 t_{1}$ 介于 0.74 至 0.99 范围内的单斜钾长石定名为正长石, 太平钾长石的 $2 t_{1}$ 与 0.74 只有 0.04 之差, 考虑产状因素, 笔者仍将该长石定名为正长石.

1995-07-28 收稿, 1996-01-13 收修改稿

* 国家自然科学基金资助项目 


\section{$2{ }^{29} \mathrm{Si}$ 核磁共振谱研究}

对太平正长石的 ${ }^{29} \mathrm{Si}$ 核磁共振谱研究, 用 Bruker MSL-400 谱仪运用固体魔角旋转探头在 室温下进行. 粉末状长石放于转子中, 转子转速为 $4 \mathrm{k} \mathrm{Hz} .{ }^{29} \mathrm{Si}$ 核的谐振频率为 $79.46 \mathrm{MHz}$. 采用单脉冲程序, 脉冲的延迟时间为 $5 \mathrm{~s}$. $90^{\circ}$ 脉冲的宽度为 $10 \mu \mathrm{s}$, 扫描数次累计 1540 次. 化 学位移以四甲基硅烷(TMS) 为参照标准.

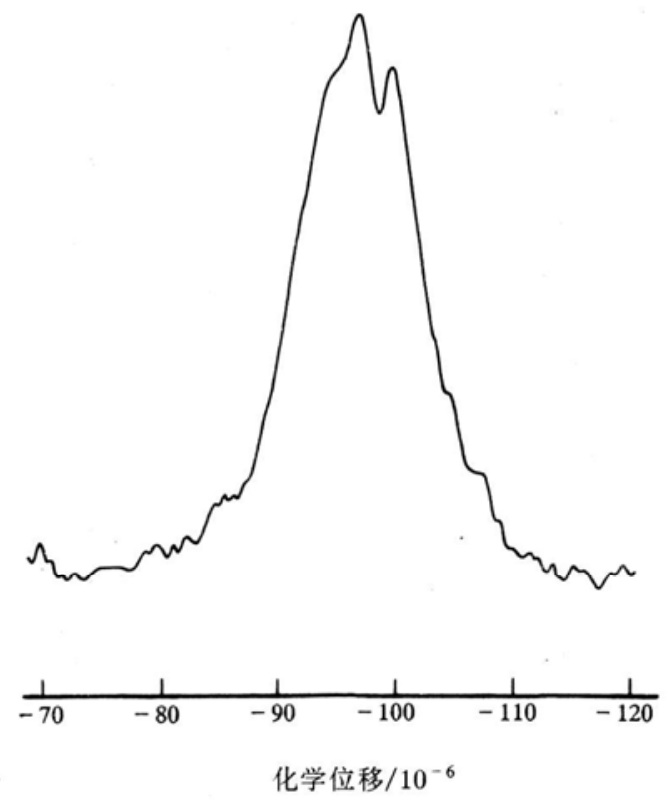

图 1 太平正长石的 ${ }^{29} \mathrm{Si}$ 魔角核磁共振谱

图 1 为太平正长石的 ${ }^{29} \mathrm{Si}$ 的魔角核磁共振谱 图. 谱由峰值位于 $-96.8 \times 10^{-6}$ 和 $-99.6 \times 10^{-6}$ 的峰和约位于 $-94.6 \times 10^{-6}$ 的肩构成. 表明该谱 至少由 3 个分量组成. 这 3 个峰的 ${ }^{29} \mathrm{Si}$ 化学位移 与微斜长石的相一致 ${ }^{[2]}$, 但宽度较宽, 且相互重叠.

\section{TEM 研究}

进行 TEM 研究的长石晶体的取向为垂直 $c$ 轴的切面. 首先制成不加盖薄片的光薄片, 然后粘 上铜网, 再将粘有铜网的样品从光薄片上取下, 用 离子薄化器减薄, 制得薄膜样品. 实验是在南京大 学现代分析中心的日本 JEOL 产的 JEM 200 CX 透 射电子显微镜上完成的, 加速电压为 $200 \mathrm{kV}$.

在 TEM 下, 太平正长石的微结构以不均匀为 特征,即不同区域的微结构不尽相同. 在一些区域 可以见到呈现席状结构, 它是由两组近于正交的衬 度变化纹相互交织而成, 如芦席纹 (图 2 左下部 分). 具这种结构的区域的 $a^{*}-b^{*}$ 面衍射花样表现为 $\gamma^{*}=90^{\circ}$, 衍射斑点呈四射星芒状, 如图 3. 这种细小的界线不分明的席状纹可以逐步变得界线明显, 并且宽度变大, 如图 2 中部所示. 与图 2 对应的选区衍射花样 (图 3) 中, 在远离透射斑的一些衍射斑点的拖曳纹中, 可见有衍射

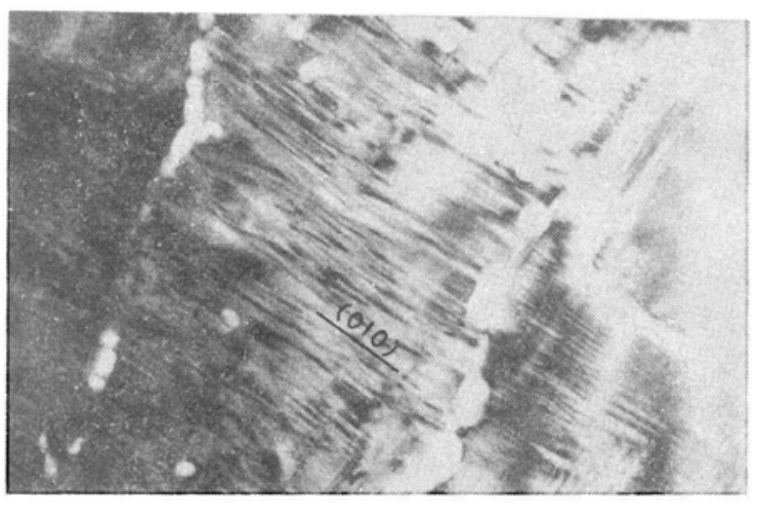

图 2 太平正长石的明场象 $(\times 50000)$

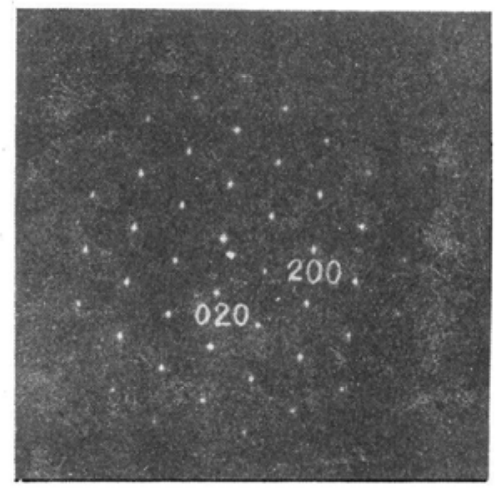

图 3 与图 2 对应的选区电子衍射花样 
极大而成卫星点. 这种点有两类: 一类与主 斑点沿平行 $b^{*}$ 轴方向排列; 另一类则平行 $a$ *轴方向分布, 说明较宽的片晶相互呈钠长 石律和肖钠长石律双晶关系. 如图 2 中部 所显示的那样, 呈双晶关系的片晶的宽度可 达 $10 \sim 20 \mathrm{~nm}$. 此外, 在样品的局部区域可 见片晶宽度达 $50 \sim 60 \mathrm{~nm}$ 的微双晶结构. 图 4 是一例. 图中显示的双晶律为肖钠长 石律. 由于片晶厚度小, 平行 $a^{*}$ 轴成行排 列的两点之间总有条纹相连. 这种区域的 选区衍射花样上 $\gamma^{*}=91.3^{\circ}$. 以上两种结构 的区域完全是无规则地混杂在一起的, 是一

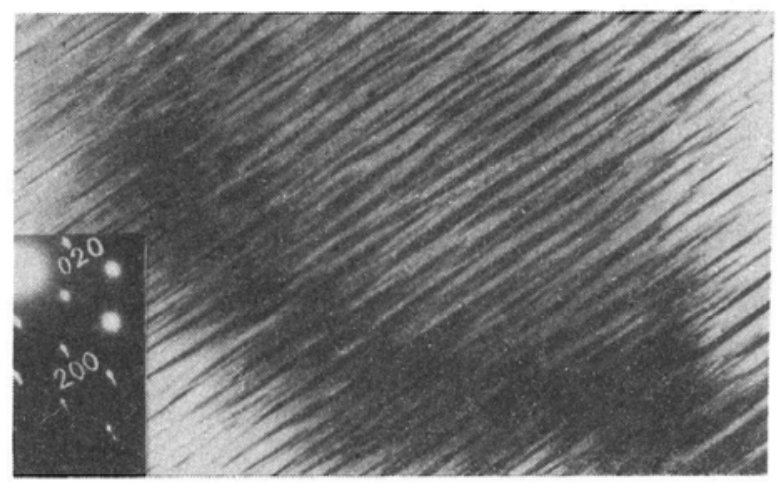

图 4 太平正长石的肖钠长石律微双晶的明场象 $\times 20000$ 种尚未达到平衡的微结构.

\section{4 微结构成因及对核磁共振谱的解释}

众所周知, 花岗岩中钾长石的初始结晶温度在其相变温度之上, 因而太平花岗岩岩脉中的 正长石的初始结晶相是一种高温相. 钾长石的高温相具 $C 2 / m$ 结构, 低温相具 $C \overline{1}$ 结构. 经 相变而形成的低温相往往都具晶畴结构 ${ }^{[4]}$. $C \overline{1}$ 空间群为 $C 2 / m$ 群的子群, 高温相 $C 2 / m$ 空 间群对其子群 $C \overline{1}$ 分解所得的陪集为 $\left\{\left(m_{[010]} \mid 000\right),\left(2_{[010]} \mid 000\right),\left(a_{[010]} \mid \frac{1}{2} \frac{1}{2} 0\right)\right.$, $\left.\left(2_{1_{\text {[010] }}} \mid \frac{1}{2} \frac{1}{2} \frac{1}{2}\right)\right\}$. 依照 Guymont 等确定的判别晶畴性质的原则 ${ }^{[5]}$, 相变过程若从 $C^{2} / m$ 结 构到 $C \overline{1}$ 结构则将出现双晶畴结构, 而且畴之间的操作元素依次为 $m$ (对称面) 和 2(二次对称 轴). 钾长石的微结构性质与这一理论推导的结果相一致. 如上所述, 在太平正长石中见到芦 席纹状及格子状微双晶两类微结构. 二者方向的一致以及存在渐变关系, 说明它们只是一种 先后的关系. 双晶是钾长石相变的最终微结构, 而芦席纹结构则是形成双晶前的一种准稳态 微结构.

芦席状结构的产生实质上是由于晶格在两个方向的畸变所致. 这种畸变的根本原因是 $\mathrm{Al}$ 在两个 $T_{1}$ 位置 $\left(T_{1} \mathrm{O}\right.$ 和 $\left.T_{1} \mathrm{~m}\right)$ 相对集中. 当一部分晶格中的 $\mathrm{Al}$ 在 $T_{1} \mathrm{O}$ 位置, 抑或 $T_{1} \mathrm{~m}$ 位 置占位, 这部分晶格(尺寸只有几个或十几个晶胞) 在对称上是三斜晶系的, 即发生了从单斜晶 系向三斜晶系的相转变, 从而出现晶格畸变. 这种晶格的畸变是一种晶格的面性波状起伏, 其 波峰和波谷是为一个平面. 从衬度像与衍射花样上四射星芒状斑点的拖曳纹可知, 一个方向 畸变的波峰(或波谷面)平行 (010) 面网, 还有一组与 $a$ 轴相垂直. 波峰(或波谷)面为未畸变 的晶格面. 由于晶格畸变并未达到双晶的程度, 在衬度像上, 只表现为衬度变化纹. 当 $\mathrm{Al}-\mathrm{Si}$ 有序化进一步发展, 波状起伏的振幅加大, 平均波长也进一步增大, 其线性尺度可从几个或十 几个晶胞扩大至几十或几百个晶胞. 波峰或波谷两侧的晶格不可能 再维持其连贯性, 进一步 调整为一种片状晶畴互成两组双晶关系的结构. 双晶界面是为前已述及的 (010)和包含 [010] 且近于垂直 $a$ 轴的两组面网. 前者以 (010) 为双晶面, 后者以 [010]为双晶轴. 这与理论推导 
的晶体由 $C 2 / m$ 结构向 $C \overline{1}$ 结构转变所产生的畴双晶的操作元素完全吻合. 在太平正长石 中, 见到的这种双晶的尺寸要在 TEM 的高倍放大下才能分辨. 在一些钾长石中, 在光学显微 镜下就可分辨了.

对太平正长石的微结构的研究揭示了它由三斜的具格子双晶的微斜长石以及晶格作波状 畸变的晶格混杂而成. 具微双晶结构的那部分晶体已明显偏离单斜对称, $\mathrm{Si}$ 在两个 $T_{2}$ 位置 和 $1 / 2 T_{1}$ 位置占位, 会在 ${ }^{29} \mathrm{Si} \mathrm{NMR}$ 谱上显示 3 个极大值; 而晶格作波状起伏畸变的那部分晶 体的谱可能会显示宽阔且峰分离不明显的谱. 太平正长石的 ${ }^{29} \mathrm{Si} \mathrm{NMR}$ 谱体现了这两种微结 构区域 ${ }^{29} \mathrm{Si}$ 原子局域结构的加和.

\section{参考文献}

1 周玲棣, 郭九香, 袁汉珍等. 碱性长石 ${ }^{29} \mathrm{Si}^{27} \mathrm{Al}$ 核磁共振谱研究. 中国科学, B 辑, 1994, 24(4):434 440

2 Kirkpatrick R J. Spectroscopic methods in mineralogy and geology. In: Reviews in Mineralogy, Vol. 18, 1988. 372 382

3 Ribbe P H. The chemistry structure and nomenclature of feldspar. In: Reviews in Mineralogy, Vol. 2, 2nd ed, 1983. 1 19

4 冯 端. 金属物理学, 第二卷. 北京: 科学出版社, 1990. 84 89

5 徐洪武, 杨南如, 薛纪越. 论相变矿物的高、低温相空间群类型与其畤结构特征之间的关系. 科学通报, 1991, 36(17): $1404 \sim 1406$ 